\title{
OPTIMAL MONETARY POLICY RULES: THE PROBLEM OF STABILITY UNDER HETEROGENEOUS LEARNING
}

\author{
Anna Bogomolova \\ Dmitri Kolyuzhnov
}
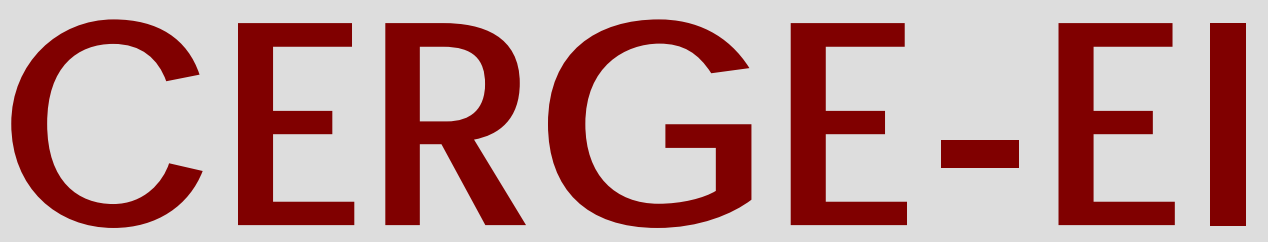

Charles University Centerfor Ec onomic Research and Graduate Education Academy of Sciences of the Czech Republic Ec onomic s Institute 


\title{
Working Paper Series $\quad 379$ (ISSN 1211-3298)
}

\section{Optimal Monetary Policy Rules: The Problem of Stability Under Heterogeneous Learning}

\author{
Anna Bogomolova \\ Dmitri Kolyuzhnov
}

CERGE-EI

Prague, December 2008 
ISBN 978-80-7343-180-8 (Univerzita Karlova. Centrum pro ekonomický výzkum a doktorské studium)

ISBN 978-80-7344-169-2 (Národohospodářský ústav AV ČR, v.v.i.) 


\title{
Optimal Monetary Policy Rules: The Problem of Stability Under Heterogeneous Learning*
}

\author{
Anna Bogomolova and Dmitri Kolyuzhnov ${ }^{\dagger}$ \\ CERGE-EI ${ }^{\ddagger}$ \\ Politických vězňů 7, 11121 Praha 1, \\ Czech Republic
}

\begin{abstract}
In this paper we extend the analysis of optimal monetary policy rules in terms of stability of an economy, started by Evans and Honkapohja (2003b), to the case of heterogeneous private agents learning. Following Giannitsarou (2003), we pose the question about the applicability of the representative agent hypothesis to learning. This hypothesis was widely used in learning literature at early stages to demonstrate convergence of an economic system under adaptive learning of agents to one of the rational expectations equilibria in the economy. We test these monetary policy rules in the general setup of the New Keynesian model that is a work horse of monetary policy models today. It is of interest to see that the results obtained by Evans and Honkapohja (2003b) for the homogeneous learning case are replicated for the case when the representative agent hypothesis is lifted.
\end{abstract}

JEL Classification: C62, D83, E31, E52

Keywords: monetary policy rules, New Keynesian model, adaptive learning, stability of equilibrium, heterogeneous agents

${ }^{*}$ The major part of this paper was written while both authors stayed as visiting Ph.D. students at the University of Cambridge, UK. The authors express special thanks to their supervisor while at Cambridge, Seppo Honkapohja, for continuous support of this research and immeasurable help and advice. All errors are the authors' responsibility.

The authors express thanks to the participants of the European Economics and Finance Society (EEFS 2006) 5th Annual Conference "European Labour Markets, Trade and Financial Flows and Economic Growth" in Heraklion, Crete, Greece May, 18-21, 2006 and the conference of the Society for Economic Dynamics (SED 2007), Prague, Czech Republic, June, 2007, for valuable discussion.

The paper won the first place in the Czech Econometric Society competition for the best Ph.D. student paper.

$\dagger\{$ Anna.Bogomolova, Dmitri.Kolyuzhnov\}@cerge-ei.cz.

${ }^{\ddagger} \mathrm{CERGE}-\mathrm{EI}$ is a joint workplace of the Center for Economic Research and Graduate Education, Charles University, and the Economics Institute of the Academy of Sciences of the Czech Republic. 


\begin{abstract}
Abstrakt
V tomto článku rozšiřujeme analýzu optimálních monetárních pravidel z hlediska stability ekonomiky, poprvé uvedené v práci Evanse a Honkapohji (2003b), na př́ipad učení heterogenních soukromých agentů. Používajíc práci Giannitsarou (2003) si pokládáme otázku, zda je možné aplikovat hypotézu reprezentativních agentů na učení. Tato hypotéza byla velmi často používána v dřívější literatuře k demonstraci konvergence ekonomického systému při adaptivním učení agentů k jednomu z rovnovážných bodů racionálních očekávání dané ekonomiky. Testujeme monetární pravidla v obecném nastavení neokeynesiánského modelu, který je tažným koněm všech dnešních modelů monetární politiky. Je také zajímavé sledovat výsledky Evanse a Honkapohji (2003b) pro případ homogenního učení, které jsou zopakovány i v případě, kdy hypotéza reprezentativních agentů je opuštěna.
\end{abstract}




\section{Introduction}

The stabilization monetary policy design problem is very often studied in the New Keynesian model. Using the environment of this model, we may study different monetary policy rules to find out which is more efficient in smoothing business cycle fluctuations and also which monetary policy rule would not lead to indeterminacy of equilibria in our model. For a comprehensive overview of various interest rate rules in the New Keynesian model, one can address Woodford (2003). Also, very often cited works on monetary policy design are Clarida, Gali and Gertler (1999, 2002). Svensson (1999) gives a clear distinction between instrument and target rules and implications of their use.

A number of recent studies also consider the New Keynesian model environment with adaptive learning of agents. Examples are works of Evans and Honkapohja (2003a, 2003b), Bullard and Mitra (2002) and Honkapohja and Mitra (2005) on stability of an economy under various policy rules. Evans and Honkapohja (2003a, $2003 \mathrm{~b}$ ) take up the issue of stability under learning for optimal monetary policies in economies with adaptive learning.

The concept of adaptive learning of agents in economic models is introduced as a specific form of bounded rationality advocated by Sargent (1993). According to the argument of Sargent (1993), it is more natural to assume that agents face the same limitations economists face (in a sense that economists have to learn the model structure and its parameter values themselves) and view agents as econometricians when forecasting the future state of the economy.

Using adaptive learning in an economy makes it possible to test the validity of the rational expectations hypothesis by checking if a given dynamic model converges over time to the rational expectations equilibrium (REE) implied by the model. It can also be used as a selection device in models with multiple equilibria. Even if the model has a unique REE, it is still of interest to see if the rational expectations (RE) hypothesis holds under learning, which is done by checking if our model under learning converges to a given REE. In both cases (multiple or unique REE), one has to check certain stability conditions. After this analysis of stability conditions, the next step could be studying policy rules for effectiveness and indeterminacy, 
assuming or making sure that the stability conditions on the model structure are satisfied.

That is why, before we start analyzing particular monetary policies for efficiency (evaluating a particular type of policy: Taylor rule, optimization-based rule with or without commitment), we should take a general type of a linear policy feedback rule, plug it into our structural form of the New Keynesian model and obtain some general linear reduced form $(\mathrm{RF})$ of this model. All things being equal (the same structural equations: Phillips and IS curves), we can obtain different RFs depending on the policy rule used by the policy maker. Hence, we obtain different REEs and different stability results. Then we should study a given reduced form for stability in order to see if a given REE is chosen. In this paper, we study the stability of a New Keynesian model under the following classification of policy rules introduced by Evans and Honkapohja (2003b).

Depending on the assumptions of the central bank about the expectations of the private agents (firms, households), Evans and Honkapohja (2003b) divide all policy rules into fundamentals-based rules and expectations-based rules. The fundamentalsbased rule is obtained if the policy maker assumes RE of private agents, while the expectations-based rule takes into account possibly non-rational expectations of agents (assuming that these expectations are observable to the central bank). ${ }^{1}$

We consider the stability question under the assumption of heterogeneous learning of agents. As has been shown in Giannitsarou (2003) and Honkapohja and Mitra (2006), stability results may be different under homogeneous and heterogeneous learning. Honkapohja and Mitra (2006) also demonstrate that stability may depend on the interaction of structural heterogeneity and learning heterogeneity, and Honkapohja and Mitra (2005) examine how structural heterogeneity in the New Keynesian model may affect stability results under various types of policy rules.

Note that though Honkapohja and Mitra (2005) consider heterogeneity in learning in the New Keynesian model, their definition of heterogeneity implies a situation

\footnotetext{
${ }^{1}$ We should note here that in Taylor-type rules the current value of interest rate depends on the current values of inflation and output gap. In this paper we study stability under feedback rules that are derived from the policy maker minimization problem, in particular, study their two categories, according to Evans and Honkapohja (2003b): fundamentals-based and expectationsbased. Stability under Taylor-type rules, which do not fall under this classification, will be studied later in a separate work.
} 
when the central bank and private agents have (possibly) different learning algorithms with (possibly) different parameters of these algorithms. They essentially consider the situation when all private agents could be considered as one representative agent, and in this sense learning of private agents considered by Honkapohja and Mitra (2005) is homogeneous. In some sense, the situation considered by Honkapohja and Mitra (2005) could be called two-sided learning in a structurally heterogeneous bivariate economy.

In this paper we do not consider learning of the central bank and assume, following Evans and Honkapohja (2003b), that the policy maker takes expectations of private agents as given or assumes and knows the exact structure of their rational expectations; at the same time we fully exploit the case when private agents have heterogeneous learning. The case of the internal central bank forecasting (that includes Taylor rules) in a situation of heterogeneous learning of private agents, which develops the model of Honkapohja and Mitra (2005) since Honkapohja and Mitra (2005) consider only the situation of a representative private agent, is the topic of our further research.

It turns out that under the fundamentals-based linear feedback policy rule (optimization-based), learning in our model never converges to the REE of the model. Evans and Honkapohja (2003b) demonstrate this instability result for the homogeneous recursive least squares (RLS) and for the stochastic gradient (SG) learning, ${ }^{2}$ while we obtain a similar instability result for the three types of heterogeneous learning considered by Giannitsarou (2003).

The other category of policy rules - expectations-based rules - is supposed to react to agents' expectations. Under certain conditions, we can have stability under such rules. Evans and Honkapohja (2003b) obtain a stability result for homogeneous RLS or for SG learning. We obtain a stability result (with conditions on the model structure) for the case of the three types of heterogeneous learning considered by

\footnotetext{
${ }^{2}$ Honkapohja and Mitra (2006) and we in this paper consider two possible algorithms used to reflect bounded rationality of agents: RLS and SG learning algorithms (which are examples of econometric learning). Their description can be found, e.g., in Evans and Honkapohja (2001), Honkapohja and Mitra (2006), Giannitsarou (2003), and Evans, Honkapohja and Williams (2005). Both are used by agents to update the estimates of the model parameters. Essentially, the difference is as follows. The RLS algorithm has two updating equations: one-for updating parameters entering the forecast functions, the other-for updating the second moments matrix (of the model state variables). The $\mathrm{SG}$ algorithm assumes this matrix fixed.
} 
Giannitsarou (2003).

Originally, when heterogeneous learning in a general setup of self-referential linear stochastic models was studied by Giannitsarou (2003), the purpose of introducing heterogeneous learning of agents was to see if the representative agents hypothesis influences stability results, i.e., if one may always apply this hypothesis. For some cases, it is demonstrated that it does make sense to consider the heterogeneous setup. Our paper is about stability under monetary policy rules, so, though we, in fact, prove that the representative agent hypothesis holds true for the New Keynesian model, the accent of our paper is shifted away from testing the importance (influence) of the representative agent hypothesis.

We, essentially, apply the stability analysis of the model under heterogeneous learning in the same manner the stability analysis of the model under homogeneous (when all agents can be substituted with a representative agent) learning is applied in Evans and Honkapohja (2003b). ${ }^{3}$ In our paper, we link the study of stability conditions under a certain category of linear monetary policy rules of Evans and Honkapohja (2003b) with the study of stability under heterogeneous learning of Giannitsarou (2003).

We first show that in the New Keynesian-type of models, stability can be analyzed using the structural parameters, whatever the type of heterogeneous learning, using the general criterion of Honkapohja and Mitra (2006). These results are the structural matrix eigenvalues sufficient and necessary conditions for stability of a structurally homogeneous model derived in this paper and the aggregate economy sufficient conditions derived in Kolyuzhnov (2006), where the concept of stability under heterogeneous learning, termed as $\delta$-stability, is introduced. Then we apply these results to derive stability and instability results under heterogeneous learning for the two categories of feedback rules: fundamentals-based and expectations-

\footnotetext{
${ }^{3}$ Evans and Honkapohja (2003b) study stability conditions under monetary policy rules for the case of homogeneous learning. Their major input is (both for the one-sided learning and the twosided learning) to have shown that under fundamentals based rules the REE of the model is always unstable, while under the expectations based rule there is always stability. In the two cases the reduced form of the model is different, which has, as a consequence, the difference in the stability results. So, the policy implication of such a stability analysis is that, given the structure of the model (the two structural New Keynesian equations), the central bank can influence (determine) the outcome of its policy by selecting the appropriate optimal monetary policy: the one that guarantees convergence to a particular REE.
} 
based, in the model with an arbitrary number of agent types.

Summarizing all the above, our work now looks, on the one hand, like a link between the study of stability under monetary policy rules for homogeneous learning of Evans and Honkapohja (2003b) and the study of stability conditions under heterogeneous learning of Giannitsarou (2003), — the link through the $\delta$-stability conditions derived by us for the general setup of Honkapohja and Mitra (2006) and through the general stability criterion of Honkapohja and Mitra (2006). On the other hand, this study can serve as one more economic example demonstrating the application of $\delta$-stability sufficient and necessary conditions.

The structure of the paper is as follows. In the next section we present the basic New Keynesian model. In Section 3 we discuss the general stability results under heterogeneous learning and the concept of $\delta$-stability introduced in Kolyuzhnov (2006). In Section 4, we give necessary and sufficient conditions for $\delta$-stability for structurally homogeneous models. Section 5 describes the two types of optimal policy rules and the structure of the reduced forms under each type. In Section 6 we provide stability and instability results for the types of optimal monetary policies considered in application to the New Keynesian model. Section 7 concludes.

\section{Model}

The model that we consider is a general New Keynesian model with observable stationary AR(1) shocks. The structural form of the model looks as follows

$$
\begin{aligned}
& x_{t}=c_{1}-\phi\left(i_{t}-\widehat{E}_{t} \pi_{t+1}\right)+\widehat{E}_{t} x_{t+1}+\chi_{1}^{\prime} w_{t} \\
& \pi_{t}=c_{2}+\lambda x_{t}+\beta \widehat{E}_{t} \pi_{t+1}+\chi_{2}^{\prime} w_{t},
\end{aligned}
$$

where the first equation is for the IS curve and the second equation is for the Phillips curve. $w_{t}=\left[\begin{array}{lll}w_{1 t} & \ldots & w_{k t}\end{array}\right]^{\prime}$ is a vector of observable $\operatorname{AR}(1) \operatorname{shocks}^{4}$,

$$
w_{i t}=\rho_{i} w_{i t-1}+\nu_{i t},\left|\rho_{i}\right|<1, \nu_{i t} \sim i i d\left(0, \sigma_{i}^{2}\right), i=\overline{1, k}
$$

\footnotetext{
${ }^{4}$ Typically, New Keynesian models include only an observable component, which is assumed to follow an $\mathrm{AR}(1)$ process. However, there are specifications including both observable and unobservable shocks. For example, Evans and Honkapohja Evans et al. (2005), who study stability rules under recursive least squares learning, include unobservable shocks to the New Keynesian model equations. In our case a more general specification with unobservable shocks would contain additional term $\Omega_{1} \epsilon_{t}$ in the IS curve and $\Omega_{2} \epsilon_{t}$ in the Phillips curve, where $\epsilon_{t}=\left[\begin{array}{lll}\epsilon_{1_{t}} & \ldots & \epsilon_{m_{t}}\end{array}\right]^{\prime}$ are unobservable shocks, $\epsilon_{i_{t}} \sim i i d\left(0, \gamma_{i}^{2}\right), i=1, \ldots, m$, not correlated with observable shocks $g_{t}$.
} 
To introduce heterogeneity in the model, we assume that we have $S$ types of private agents characterized by their share $\zeta_{h}>0$ in the economy, $\sum_{h=1}^{S} \zeta_{h}=1$. So, $\widehat{E}_{t} x_{t+1}=\sum_{h=1}^{S} \zeta_{h} \widehat{E}_{t}^{h} x_{t+1}, \widehat{E}_{t} \pi_{t+1}=\sum_{h=1}^{S} \zeta_{h} \widehat{E}_{t}^{h} \pi_{t+1}$, where $\widehat{E}_{t}^{h} x_{t+1}$ and $\widehat{E}_{t}^{h} \pi_{t+1}$ are expectations (in general, non-rational) of private agent of type $h$ made at time $t$ about the next period output gap and inflation, respectively.

The model (1), (2) and (3) is a general formulation of models derived from microfoundations that are considered in macroeconomics and monetary economics literature. The two basic equations of the New Keynesian model, which are the Phillips curve and the IS curve are derived from the optimal problems of the representative household and the representative monopolistically competitive firm, with the assumption of Calvo (1983) pricing mechanism in the firms' price-setting decision. So the two New Keynesian curves are derived using the optimality conditions of the private agents (households and firms). The derivation of these two curves for the standard New Keynesian model setup can be found, e.g., in Walsh (2003). The description of the New Keynesian model can also be found in Woodford (1996, 2003) and in Christiano, Eichenbaum and Evans (2001).

In solving their optimization problems, private agents are assumed to take the interest rate (entering the IS curve equation) as given. The interest rate, in turn, is set by the policy maker - the central bank. In various studies of monetary policy issues (in the New Keynesian framework), it is normally assumed that the policy maker uses some linear feedback rule to set the interest rate. In general, a feedback

Of course, these unobservables do not bring a difference into the stability results (that is why we omit them in the model analyzed), but introducing them into the setup has its own reasoning. For example, it makes sense to introduce unobservable shocks into structural equations when we consider central bank learning structural coefficients of the model. If we have only observable shocks (which play a role of just another regressor - some exogenous variable) as well as other observable regressors, we will evaluate the equations' coefficients exactly if we have a sufficient number of observations. In this case learning is trivial: the convergence will be very quick if initially we did not have enough observations, but gained them over a short period of time.

If we think of how these unobservable shocks can emerge at the micro foundations level, we may think of the following economic interpretation. For example, let us assume that preference and technology shocks consist of observable and unobservable components. As for preference shocks, we can imagine a qualitative change in our preferences, such that we know how the shock has changed our preferences qualitatively, but we cannot precisely measure this change quantitatively. A similar interpretation can be given to the technological shock. What we have measured enters as an observable component, while the measurement error (which always exists since we assume that our quantitative measurement of any change is imprecise) is treated as an unobservable component. 
rule that is derived from the loss function minimization problem determines how the interest rate reacts to the expected values of the model's endogenous variables (inflation and output gap in the New Keynesian model) and the model's exogenous variables (various shocks, e.g., technology shock, preference shock, cost-push shock). Instrument rules, like Taylor-type rules, are designed to respond to the target variables (e.g., inflation and output gap). As is noted in the introduction, Taylor-type rules will be considered in a separate study.

Plugging the feedback rule into the IS curve equation, we obtain the model reduced form. Using the same New Keynesian equations (IS and Phillips curves), we can obtain different reduced forms for different policy rules, i.e. other things being equal, the reduced form structure depends on the policy rule. It depends not only on the type of it (Taylor or optimization-based), but, as is demonstrated by Evans and Honkapohja (2003b), on the assumption of the central bank about private agents expectations, resulting either in the fundamentals-based or in the expectations-based category of feedback rules.

After plugging some monetary policy rule of the central bank $i_{t}$, assuming that the central bank knows expectations of private agents or assumes and knows the form of rational expectations of agents (we will talk about the types of optimal monetary policy rules later), the model can be written in the reduced form that has a general representation of a bivariate system with a stationary $\mathrm{AR}(1)$ observable shocks process

$$
\begin{aligned}
y_{t}= & \alpha+A \hat{E}_{t} y_{t+1}+B w_{t}, \\
y_{t}= & {\left[\begin{array}{ll}
\pi_{t} & x_{t}
\end{array}\right]^{\prime} } \\
& \text { and }(3) .
\end{aligned}
$$

In what follows, for the derivation of our stability results we may allow for some generalization (as it is just a matter of notation compared to the bivariate model) and consider a multivariate (not just bivariate) system (4) with a stationary $\operatorname{AR}(1)$ observable shocks process (3).

In our notation, the reduced form is written in such a way that it includes all factors that appear in the structural form. This means that the absence of some factor in the reduced form in our notation is expressed by the corresponding zero 
column of matrix $B$. Note that here we adopt such a notation in order to be able later to consider different specifications of learning algorithms that include factors from different sets. ${ }^{5}$ So our notation is the most general that can be.

In adaptive learning models of bounded rationality it is assumed that agents do not know the rational expectations equilibrium and instead have their own understanding of the relation between variables in the model. The coefficients in this relation (that are called beliefs) are updated each period as new information on observed variables arrives (in this respect agents are modeled as if they were statisticians, or econometricians ) For the beginning, we assume that agents have the following perceived relation among the variables in the economy, which is called the perceived law of motion (PLM)

$$
y_{t}=a^{h}+\Gamma^{h} w_{t},
$$

$$
\text { with } a^{h}=\left[\begin{array}{ll}
a_{1}^{h} & a_{2}^{h}
\end{array}\right]^{\prime}, \Gamma^{h}=\left[\begin{array}{cccc}
\gamma_{11}^{h} & \gamma_{12}^{h} & \ldots & \gamma_{1 k}^{h} \\
\gamma_{21}^{h} & \gamma_{22}^{h} & \ldots & \gamma_{2 k}^{h}
\end{array}\right] \text { in the bivariate case, }
$$

that includes all components of $w_{t}$. A bit later we weaken this assumption. Though we assume that the parameters of the PLM may differ across agents, we assume that the structure of the PLMs is the same for all agents. We may also write the average (or aggregate) PLM using the weights of agents.

$$
y_{t}=a+\Gamma w_{t}, \text { where } a=\sum_{h=1}^{S} \zeta_{h} a^{h}, \Gamma=\sum_{h=1}^{S} \zeta_{h} \Gamma^{h} .
$$

Thus agents have the following forecast functions based on their PLMs

$$
\widehat{E}_{t}^{h} y_{t+1}=a^{h}+\Gamma^{h} \operatorname{diag}\left(\rho_{1}, \ldots, \rho_{k}\right) w_{t}
$$

and consequently the average forecast function is given by

$$
\widehat{E}_{t} y_{t+1}=\sum_{h=1}^{S} \zeta_{h}\left(a^{h}+\Gamma^{h} \operatorname{diag}\left(\rho_{1}, \ldots, \rho_{k}\right) w_{t}\right)=a+\Gamma \operatorname{diag}\left(\rho_{1}, \ldots, \rho_{k}\right) w_{t} .
$$

After plugging the average forecast function (7) corresponding to the average PLM (6) into the reduced form (4), we derive the actual law of motion (ALM)

$$
y_{t}=A a+\alpha+\left(A \Gamma \operatorname{diag}\left(\rho_{1}, \ldots, \rho_{k}\right)+B w_{t}\right) .
$$

\footnotetext{
${ }^{5}$ An example when a model reduced form may not include all shocks that are present as factors in the model structural form can be found in Evans and Honkapohja (2003b), who used the New Keynesian model setup of Clarida, Gali and Gertler (1999).
} 
The rational expectations equilibrium (REE) defined as $E_{t} y_{t+1}=\widehat{E}_{t} y_{t+1}=\widehat{E}_{t}^{i} y_{t+1}$ (see, e.g., Sargent (1993) or Evans and Honkapohja (2001) for the meaning of the $\mathrm{RE}$ concept) can be calculated by equating the parameters of the average PLM (6) with the corresponding parameters of the ALM (8). If we define the $T$-map as a mapping of beliefs from the average PLM (6) to the ALM (8),

$$
T(a, \Gamma)=\left(A a+\alpha, A \Gamma \operatorname{diag}\left(\rho_{1}, \ldots, \rho_{k}\right)+B\right),
$$

we will be able to write the REE condition as $T(a, \Gamma)=(a, \Gamma)$.

Now we will widen the set of PLMs considered. Let us start with the following definition.

Definition 1 The active factors set is a subset of a set of histories of $w_{i_{t}}$ up to time $t$ and a constant used by agents in their PLMs. ${ }^{6}$

Following the definition, we renumber the subscripts corresponding to regressors that are included into agents' active factors set from 1 to $k^{\prime}$, and denote the set of subscripts taken from $\{1, \ldots, k\}$ corresponding to the active factors set as $\widetilde{I}$. Assuming, as before, that all agents have the same structure of their individual PLMs, agents now are assumed to have the following average perceived law of motion (PLM)

$$
y_{t}=a+\widetilde{\Gamma} \widetilde{w}_{t}
$$

$$
\text { with } a=\left[\begin{array}{ll}
a_{1} & a_{2}
\end{array}\right]^{\prime}, \widetilde{\Gamma}=\left[\begin{array}{cccc}
\widetilde{\gamma}_{11} & \widetilde{\gamma}_{12} & \ldots & \widetilde{\gamma}_{1 k^{\prime}} \\
\widetilde{\gamma}_{21} & \widetilde{\gamma}_{22} & \ldots & \widetilde{\gamma}_{2 k^{\prime}}
\end{array}\right] \text { in the bivariate case, }
$$

where $\widetilde{w}_{t}$ consists of the components of $w_{t}$ included in agents' active factors set. Consequently, $T$-map (9) can be rewritten as

$$
\widetilde{T}(a, \widetilde{\Gamma})=\left(A a+\alpha, A \widetilde{\Gamma} \operatorname{diag}\left(\rho_{1}, \ldots, \rho_{k}\right)+\widetilde{B}\right) .
$$

where $\widetilde{B}$ consists of columns of matrix $B$ that correspond to the active factors set.

Similarly, one may try to write the REE condition as $\widetilde{T}(a, \widetilde{\Gamma})=(a, \widetilde{\Gamma})$. However, in this case, it is clear that for the existence of a REE, agents have to include into

\footnotetext{
${ }^{6}$ Note that by the active factors set we mean not the variables that agents are actually aware of at time $t$, but essentially those that are used by agents in their PLMs (a subset that may be smaller than the subset of actually available variables).
} 
their active factors set those factors $w_{i_{t}}$ that correspond to non-zero columns of matrix $B$ in the reduced form. A PLM which consists only of such factors is a PLM that corresponds to the so-called minimal state variable (MSV) solution. Also, in the above PLMs we have used the following assumption.

Assumption 1 Agents include in their PLM of each endogenous variable all factors from their active factors set. ${ }^{7}$

Essentially, Assumption 1 postulates that we may write each agent's PLM equations in matrix form, without a priori setting coefficients at some factors to zero. In addition, we assume that all agents use the same set of factors (which in matrix form means that they use the same vector). We also note here that a similar assumption on the matrix formulation of PLMs has been made by Giannitsarou (2003) and Honkapohja and Mitra (2006). ${ }^{8}$

The Propositions below state the necessary and sufficient conditions for the existence and for the uniqueness of a REE in a general multivariate model with stationary $\mathrm{AR}(1)$ observable shocks. These conditions are well-known, but we prefer to state them here for the reader's convenience. To formulate the following propositions, we return back to the initial numbering of shocks, denote the constant term in the active factors set of agents as $w_{0}$ and take $\rho_{0}=1$ and $B^{0}=\alpha$. So, now $i$ takes integer values from 0 to $k$. We will denote this set as $I_{0}$ and the corresponding set of subscripts taken from $I_{0}=\{0,1, \ldots, k\}$ as $\widetilde{I}_{0}$. Note that the constant term is always included as a factor in any active factors set, therefore 0 always belongs to $I_{0}$.

\footnotetext{
${ }^{7}$ So we exclude situations when agents do not include into the PLM equation of one endogenous variable some factor having a zero coefficient in matrix $B$ of the reduced form, while including the same factor in the PLM equation of the other endogenous variable, with this factor having a non-zero coefficient in matrix $B$ of the reduced form. We assume that agents do not know the true structure of the reduced form and use all the available information to form their expectations. So, if one factor is present in one PLM equation, it is present in another PLM equation.

${ }^{8}$ Notice that here we also do not consider situations of the restricted perceptions equilibrium (RPE), the discussion of which may be found, for example in Evans and Honkapohja (2001). In our terminology, for the situation of the RPE, one has to assume that agents do not include into their active factors set some of the factors that are present in a unique REE, that is, factors that correspond to non-zero coefficients in matrix $B$. Here we introduce the notion of the active factors set only to allow for considering the PLMs not only corresponding to the MSV, but also those PLMs that include more factors than enough to determine a unique REE. It is done to derive the "strong $\delta$-stability" or "strong $\delta$-instability result." (Compare to the notion of "strong $E$-stability" in the homogeneous learing literature.)
} 
Proposition 1 (Necessary and sufficient conditions for existence of a REE) Under Assumption 1, a REE solution exists if and only if agents' active factors set includes among others all $w_{i}$ such that $B^{i} \neq 0$ in the reduced form and $\operatorname{rank}\left(\rho_{i} A-I\right)=$ $\operatorname{rank}\left(\rho_{i} A-I, B^{i}\right)$ for $i$ such that $\operatorname{det}\left(\rho_{i} A-I\right)=0$ and $B^{i} \neq 0$.

Proof. See Appendix A.

Proposition 2 (Necessary and sufficient conditions for existence and uniqueness of a REE): Under Assumption 1, a REE solution exists and is unique if and only if agents' active factors set includes, among others, all $w_{i}$ such that $B^{i} \neq 0$ in the reduced form and for all $w_{i}$ included, $\operatorname{det}\left(\rho_{i} A-I\right) \neq 0$.

Proof. See Appendix A.

So, in what follows we always assume that Assumption 1 and the necessary and sufficient conditions ${ }^{9}$ for existence of a REE hold true. Basically, we assume that in both equations of their PLM, agents use at least all the regressors that appear in the right-hand side of the reduced form (4), and that the REE solution (either unique or multiple) exists under this PLM. That is, in principle, we consider all possible PLMs that satisfy these conditions.

After specifying PLMs of agents and conditions for existence and uniqueness of the REE we are ready to introduce heterogeneous learning of agents in the economy considered and derive conditions for stability of the REE under this learning. Then we use these conditions to study stability under heterogenous learning in the general New Keynesian model when optimal monetary policy rules are applied.

\section{Heterogeneous Learning and the Concept of $\delta-$ stability}

The model (4) and (3) that we consider belongs to the class of multivariate forwardlooking economic models. Thus we naturally employ the general framework and

\footnotetext{
${ }^{9}$ The propositions above have a similar meaning to Proposition 1 of Honkapohja and Mitra (2006): again, the condition requires matrices participating in the derivation of the RE values of beliefs to be invertible. So, the above propositions stress that we are aware of cases when an REE may not exist and of the conditions that are required for its existence (and uniquness).
} 
notation from Honkapohja and Mitra (2006), who were the first to formulate the general criterion for stability of a multivariate forward-looking economy under heterogeneous learning.

Honkapohja and Mitra (2006) consider the class of linear structurally heterogeneous forward-looking models with $S$ types of agents with different forecasts presented by

$$
\begin{aligned}
y_{t} & =\alpha+\sum_{h=1}^{S} A_{h} \hat{E}_{t}^{h} y_{t+1}+B w_{t}, \\
w_{t} & =F w_{t-1}+v_{t}
\end{aligned}
$$

where $y_{t}$ is an $n \times 1$ vector of endogenous variables, $w_{t}$ is a $k \times 1$ vector of exogenous variables, $v_{t}$ is white noise, $\hat{E}_{t}^{h} y_{t+1}$ are (in general, non-rational) expectations of the endogenous variable by agent type $h, M_{w}=\lim _{t \rightarrow \infty} w_{t} w_{t}^{\prime}$ is positive definite, and $F$ is such that $w_{t}$ follows a stationary VAR process.

The PLM is presented by (6). Part of agent types, $h=\overline{1, S_{0}}$, is assumed to use the RLS learning algorithm, while the rest, $h=\overline{S_{0}+1, S}$, are assumed to use the SG learning algorithm. ${ }^{10}$ Moreover, all of them are assumed to use possibly different degrees of responsiveness to the updating function that are presented by different degrees of inertia $\delta_{i}>0$, constant coefficients before the common for all agents decreasing gain sequence in the learning algorithm. ${ }^{11}$

It is worth noting that the model (4) and (3) that we consider belongs to the subclass of models considered by Honkapohja and Mitra (2006), namely, a class of structurally homogeneous forward looking models. Structural heterogeneity in the setup of Honkapohja and Mitra (2006) is expressed through matrices $A_{h}$, which are assumed to incorporate mass $\zeta_{h}$ of each agent type. That is, $A_{h}=\zeta_{h} \cdot \hat{A}_{h}$, where $\hat{A}_{h}$ is defined as describing how agents of type $h$ respond to their forecasts. So these are the structural parameters characterizing a given economy. Those may be basic characteristics of agents, like the ones describing their preferences, endowments, and technology. Structural heterogeneity means that all $\hat{A}_{h}$ 's are different for different types of agents. When $\hat{A}_{h}=A$ and $\sum \zeta_{h}=1$, the economy is structurally

\footnotetext{
${ }^{10}$ Essentially, the part of agents using RLS are assumed to be more sophisticated in their learning, because from the econometric point of view, the RLS algorithm is more efficient since it uses information on the second moments.

${ }^{11}$ Honkapohja and Mitra (2006) use a more general formulation of degrees of inertia.
} 
homogenous.

When we apply conditions for a structurally homogeneous economy, $A_{h}=\zeta_{h} A$, where $\sum_{h=1}^{S} \zeta_{h}=1$, and $1>\zeta_{h}>0$, to the model (10) and (11) considered by Honkapohja and Mitra (2006), we get

$$
\begin{aligned}
& y_{t}=\alpha+\sum_{h=1}^{S} A_{h} \hat{E}_{t}^{h} y_{t+1}+B w_{t}=\alpha+\sum_{h=1}^{S} \zeta_{h} A \hat{E}_{t}^{h} y_{t+1}+B w_{t}= \\
&=\alpha+\underbrace{A \sum_{h=1}^{S} \zeta_{h} \hat{E}_{t}^{i} y_{t+1}}_{\hat{E}_{t}^{\text {aver }} y_{t+1}}+B w_{t},
\end{aligned}
$$

which is exactly the formulation of the structurally homogeneous model considered by Giannitsarou (2003). ${ }^{12}$ Thus conditions for stability valid for the (more general) class of structurally heterogeneous forward-looking models remain valid for the class of structurally homogeneous models.

After denoting $z_{t}=\left(1, w_{t}\right)$ and $\Phi_{h, t}=\left(a_{h, t}, \Gamma_{h, t}\right)$, the formal presentation of the learning algorithms in this model can be written as follows.

RLS: for $h=\overline{1, S_{0}}$

$$
\begin{aligned}
\Phi_{h, t+1} & =\Phi_{h, t}+\alpha_{h, t+1} R_{h, t}^{-1} z_{t}\left(y_{t}-\Phi_{h, t}^{\prime} z_{t}\right)^{\prime} \\
R_{h, t+1} & =R_{h, t}+\alpha_{h, t+1}\left(z_{t-1} z_{t-1}^{\prime}-R_{h, t}\right)
\end{aligned}
$$

SG: for $h=\overline{S_{0}+1, S}$

$$
\Phi_{h, t+1}=\Phi_{h, t}+\alpha_{h, t+1} z_{t}\left(y_{t}-\Phi_{h, t}^{\prime} z_{t}\right)^{\prime}
$$

Honkapohja and Mitra (2006) show that stability of the REE, $\Phi_{t}$, in this model is

\footnotetext{
${ }^{12}$ Heterogeneous learning in the structurally homogeneous case was considered by Giannitsarou (2003) for a more general class of self-referential linear stochastic models, which includes in itself the case of forward-looking models. Since our setup does not assume lagged endogenous variables, we concentrate on the structurally homogeneous case of forward-looking models that are a subclass of models considered by Giannitsarou (2003) and at the same time are a special case of the setup of Honkapohja and Mitra (2006).
} 
determined by stability of the $\mathrm{ODE}^{13}$ :

$$
\begin{aligned}
\frac{d \Phi_{h}}{d \tau} & =\delta_{h}\left(T\left(\Phi^{\prime}\right)^{\prime}-\Phi_{h}\right), h=\overline{1, S_{0}} \\
\frac{d \Phi_{h}}{d \tau} & =\delta_{h} M_{z}\left(T\left(\Phi^{\prime}\right)^{\prime}-\Phi_{h}\right), h=\overline{S_{0}+1, S}
\end{aligned}
$$

where $M_{z}=\lim _{t \rightarrow \infty} E z_{t} z_{t}^{\prime}$.

The conditions for stability of this ODE give the general criterion for stability result for this class of models presented in Proposition 5 in Honkapohja and Mitra (2006). In the economy (10) and (11), the mixed RLS/SG learning (12) and (13) converges globally (almost surely) to the minimal state variable (MSV) solution if and only if matrices $D_{1} \Omega$ and $D_{w} \Omega_{F}$ have eigenvalues with negative real parts, where

$$
\begin{aligned}
& D_{1}=\left(\begin{array}{ccc}
\delta_{1} I_{n} & \cdots & 0 \\
\vdots & \ddots & \vdots \\
0 & \cdots & \delta_{S} I_{n}
\end{array}\right), \Omega=\left(\begin{array}{ccc}
A_{1}-I_{n} & \cdots & A_{S} \\
\vdots & \ddots & \vdots \\
A_{1} & \cdots & A_{S}-I_{n}
\end{array}\right) \\
& D_{w}=\left(\begin{array}{ccc}
D_{w 1} & \cdots & 0 \\
\vdots & \ddots & \vdots \\
0 & \cdots & D_{w S}
\end{array}\right), \begin{array}{l}
D_{w h}=\delta_{h} I_{n k}, h=\overline{1, S_{0}} \\
D_{w h}=\delta_{h}\left(M_{w} \otimes I_{n}\right), h=\overline{S_{0}+1, S}
\end{array} \\
& \Omega_{F}=\left(\begin{array}{ccc}
F^{\prime} \otimes A_{1}-I_{n k} & \cdots & F^{\prime} \otimes A_{S} \\
\vdots & \ddots & \vdots \\
F^{\prime} \otimes A_{1} & \cdots & F^{\prime} \otimes A_{S}-I_{n k}
\end{array}\right) \text {, }
\end{aligned}
$$

with $\otimes$ denoting the Kronecker product.

Note, that agents in the setup of Honkapohja and Mitra (2006) are assumed to use PLMs that correspond to the so-called MSV solution, i.e., include all factors that appear in the right hand side of the reduced form. However, Honkapohja and Mitra (2006) in their proof of conditions for stability of the system do not have restrictions on the matrix $B$. This means that we may, in principle, consider additional factors in learning that enter the reduced form with zero coefficients in matrix $B$ for all agents. This means that we may consider the criterion conditions for all possible PLMs that

\footnotetext{
${ }^{13}$ In the general case, to obtain the associated ODE, one has to take the math expectation of the RHS term (at the gain sequence) from the stochastic recursive algorithm (SRA) specification of a learning algorithm, with respect to the limiting distribution of the state vector. See Ch. 6.2 in Evans and Honkapohja (2001) for assumptions on the learning rule and state dynamics that have to hold so that we are able to apply the theory on SRA and local convergence analysis and the general formula for $\operatorname{ODE}(6.5)$ on p. 126.
} 
include (among others) all factors that appear in the right hand side of the reduced form, satisfying conditions for existence specified in the previous chapter.

Kolyuzhnov (2006) shows that in the "diagonal" environment, namely

$$
F=\operatorname{diag}\left(\rho_{1}, \ldots, \rho_{k}\right), M_{w}=\operatorname{diag}\left(\frac{\sigma_{1}^{2}}{1-\rho_{1}^{2}}, \ldots, \frac{\sigma_{k}^{2}}{1-\rho_{k}^{2}}\right),
$$

which we consider in this paper, the problem of finding stability conditions for both $D_{1} \Omega$ and $D_{w} \Omega_{F}$ is simplified to finding stability conditions for $D_{1} \Omega$ and $D_{1} \Omega_{\rho l}$, where $\Omega_{\rho_{l}}$ is obtained from $\Omega$ by substituting all $A_{h}$ with $\rho_{l} A_{h}$, where $\left|\rho_{l}\right|<1$ as $w_{t}$ follows a stationary $\operatorname{VAR}(1)$ process.

$$
\Omega_{\rho_{l}}=\left(\begin{array}{ccc}
\rho_{l} A_{1}-I_{n} & \cdots & \rho_{l} A_{S} \\
\vdots & \ddots & \vdots \\
\rho_{l} A_{1} & \cdots & \rho_{l} A_{S}-I_{n}
\end{array}\right), \forall l=0, \ldots, k,\left(\rho_{0}=1\right) .
$$

Kolyuzhnov (2006) uses a special blocked-diagonal structure of matrix $D_{1}$, which is the feature of the dynamic environment in this class of models. In a sense, these positive diagonal $D$-matrices may now be called positive blocked - diagonal $\delta$-matrices. This makes it possible to formulate the concept of $\delta$-stability by analogy to the terminology of the concept of $D$-stability about matrices that remain stable under multiplication by a diagonal matrix with positive elements, studied for example in Johnson (1974).

Definition 2 Given n, the number of endogenous variables, and $S$, the number of agent types, $\delta$-stability is defined as stability of the economy under structurally heterogeneous mixed RLS/SG learning for any (possibly different) degrees of inertia of agents, $\delta>0$.

$\delta$-stability, thus formulated, has the same meaning in models with heterogeneous learning described above as has the $E$-stability condition in models with homogeneous RLS learning. The E-stability condition is a condition for asymptotic stability of an REE under homogeneous RLS learning. The REE of the model is stable if it is locally asymptotically stable under the following ODE:

$$
\frac{d \theta}{d \tau}=T(\theta)-\theta
$$


where $\theta$ are the estimated parameters from agents PLMs, $T(\theta)$ is a mapping of the PLM parameters into the parameters of the actual law of motion (ALM), which is obtained when we plug the forecast functions based on the agents' PLMs into the reduced form of the model, and $\tau$ is a "notional" ("artificial") time. The fixed point of this ODE is the REE of the model. ${ }^{14}$

Note that the $\delta$-stability concept comprises stability under the three types of heterogeneous learning considered by Giannitsarou (2003). It is worth noting that in the case of heterogeneous learning in a structurally homogeneous economy, which we employ in the current setup, the criterion of Honkapohja and Mitra (2006) is simplified to conditions on the Jacobians considered by Giannitsarou (2003). First, as has been discussed before, to get the structurally homogeneous economy as discussed before, one has to replace $A_{i}$ in the setup of Honkapohja and Mitra (2006) with $\zeta_{i} A$. After that, one has to make the following simplifications in the setup corresponding to a particular type of heterogeneous learning considered.

The first type of heterogeneous learning is characterized by different initial perceptions of agents and equal degrees of inertia. This type is termed transiently heterogeneous learning by Honkapohja and Mitra (2006). The condition for stability under this learning is easily derived from the criterion above by setting all $\delta$ 's to be equal, and setting $S_{0}$ to $S$ or to 0 in order to get transiently heterogeneous RLS or SG learning, respectively.

The second type of heterogeneous learning considered by Giannitsarou (2003) is such that agents use different degrees of inertia and the same type of learning algorithm (RLS or SG). This is what Honkapohja and Mitra (2006) call persistently heterogeneous learning in a weak form. The Jacobians for this case are easily derived by setting $S_{0}$ to $S$ or to 0 in order to get heterogeneous RLS or SG learning, respectively, and allowing for possibly different $\delta$ 's.

The third type of heterogeneous learning considered by Giannitsarou (2003) is

\footnotetext{
${ }^{14}$ Notice that $\delta$-stability conditions on the Jacobian in the general forward-looking model of Honkapohja and Mitra (2006) do not depend on the particular equilibrium point (in case of multiple equilibria), because the system of differential equations is linear in this setup, in which case the first derivatives of the RHS of the associated ODE do not depend on a particular value of a RE equilibrium. So if stability conditions are satisfied for a given Jacobian, then all equilibrium points are stable. Convergence to a particular point depends on the initial conditions. In this paper we do not consider how equilibrium selection is made.
} 


\begin{tabular}{|c|c|c|c|}
\hline \multirow[t]{3}{*}{ Type of heterogeneity } & \multirow[t]{3}{*}{ Type of learning } & \multicolumn{2}{|c|}{$\begin{array}{l}\text { Assumptions in the general } \\
\text { H\&M (2006) model }\end{array}$} \\
\hline & & $\begin{array}{l}\text { structurally } \\
\text { heterogeneous }\end{array}$ & \begin{tabular}{|l|} 
structurally \\
homogeneous
\end{tabular} \\
\hline & & $A_{h}=\zeta_{h} \hat{A}_{h}$ & $A_{h}=\zeta_{h} A$ \\
\hline $\begin{array}{l}\text { I Different initial perceptions } \\
\text { (transiently heterogeneous } \\
\text { learning) }\end{array}$ & $\begin{array}{l}\text { RLS } \\
\text { SG }\end{array}$ & \multicolumn{2}{|c|}{$\begin{array}{l}\delta_{h}=\delta \text { for all } h, S_{0}=S \\
\delta_{h}=\delta \text { for all } h, S_{0}=0\end{array}$} \\
\hline $\begin{array}{l}\text { II Different degrees of inertia } \\
\text { (persistently heterogeneous } \\
\text { learning in a weak form) }\end{array}$ & $\begin{array}{l}\text { RLS } \\
\text { SG }\end{array}$ & \multicolumn{2}{|l|}{$\begin{array}{l}S_{0}=S \\
S_{0}=0\end{array}$} \\
\hline $\begin{array}{l}\text { III Different learning algorithms } \\
\text { (persistently heterogeneous } \\
\text { learning in a strong form) }\end{array}$ & RLS and SG & & \\
\hline
\end{tabular}

Table 1: Types of heterogeneity in learning.

characterized by possibly different initial perceptions, possibly different degrees of inertia, and by different agents using different learning algorithms (RLS or SG). Such kind of learning Honkapohja and Mitra (2006) call persistently heterogeneous learning in a strong form. The stability Jacobians for this case are derived by writing the general criterion for stability for the structurally homogeneous case, i.e., by setting $A_{i}=\zeta_{i} A$.

The relation between the above-described formulations of the types of heterogeneous learning by Giannitsarou (2003) and by Honkapohja and Mitra (2006) can be conveniently summarized in the following table ${ }^{15}$ :

Notice that in the "diagonal" case (15), $\delta$-stability does not depend on $S_{0}$. Thus

\footnotetext{
${ }^{15}$ Note that there is one type of heterogeneous learning that was not introduced by Giannitsarou (2003) and is introduced here. It is heterogeneity in degrees of inertia under which all types of agents use the SG learning algorithm. Although Honkapohja and Mitra (2006) have the general criterion for stability in this case (as discussed above), their formulation includes only forward-looking models. In the general setup of self-referential structurally homogeneous models of Giannitsarou (2003), the stability conditions under such type of learning (in Giannitsarou (2003) notation, naturally extended from her proofs) would depend on the stability of matrix $J_{2}^{S G}\left(\Phi_{f}\right)=\operatorname{diag}\left(\delta_{1}, \ldots, \delta_{S}\right) \otimes I \otimes M\left(\Phi_{f}\right) J_{1}^{L S}\left(\Phi_{f}\right)$, where $\Phi_{f}$ is an REE, $M\left(\Phi_{f}\right)$ is defined similarly to $M_{z}$ and $J_{1}^{L S}\left(\Phi_{f}\right)$ is a Jacobian that defines stability in case of the first type of heterogeneity (different initial perceptions of agents) when all agents use RLS learning. For details, see Giannitsarou (2003) . Again, it is clear that in the forward-looking case these conditions for stability fall under the general stability criterion of Honkapohja and Mitra (2006) with $S_{0}=0$ (see the table above).
} 
if the economy (10), (11) and (15) is $\delta$-stable, it is stable under all three types of heterogeneous learning and under RLS and SG homogeneous learning.

\section{Conditions for $\delta$-stability of Structurally Ho- mogeneous Models}

After establishing the universal role of the concept of $\delta$-stability for stability under all three types of heterogeneous learning discussed above, we present necessary and sufficient conditions. First, we provide the reader with a set of sufficient conditions for $\delta$-stability applicable to our setup, that is, for a class of structurally homogeneous models. We present (without proofs) the so-called aggregate economy sufficient condition for the case of a structurally homogeneous model and the "same sign" sufficient condition for the case of a structurally heterogeneous bivariate economy that were derived in Kolyuzhnov (2006)

Proposition 3 For the structurally homogeneous economy (4) and (3) to be $\delta$ stable, it is sufficient that at least one of the following limiting aggregated $\beta$-coefficients (which are the coefficients before the expectation term of a one-dimensional forwardlooking aggregate economy model. For details see Kolyuzhnov (2006)): $\max _{i} \sum_{j}\left|a_{i j}\right|$ and $\max _{j} \sum_{i}\left|a_{i j}\right|$ are less than one, where $a_{i j}$ denotes an element in the $i^{\text {th }}$ row and the $j^{\text {th }}$ column of $A$.

Proposition 4 In case $n=2$, the economy (10), (11) and (15) is $\delta$-stable if the corresponding matrix $\Omega$, defined in (14), is stable and the following "same sign" condition holds true:

$\operatorname{det}\left(-\rho_{l} A_{i}\right) \geq 0,\left[\operatorname{det} \operatorname{mix}\left(-\rho_{l} A_{i},-\rho_{l} A_{j}\right)+\operatorname{det} \operatorname{mix}\left(-\rho_{l} A_{j},-\rho_{l} A_{i}\right)\right] \geq 0, i \neq j, M_{1}\left(-\rho_{l} A_{i}\right) \geq 0$ or

$\operatorname{det}\left(-\rho_{l} A_{i}\right) \leq 0,\left[\operatorname{det} \operatorname{mix}\left(-\rho_{l} A_{i},-\rho_{l} A_{j}\right)+\operatorname{det} \operatorname{mix}\left(-\rho_{l} A_{j},-\rho_{l} A_{i}\right)\right] \leq 0, i \neq j, M_{1}\left(-\rho_{l} A_{i}\right) \leq 0$, $\forall l=0,1, \ldots, k,\left(\rho_{0}=1\right)$,

where mix $\left(-\rho_{l} A_{i},-\rho_{l} A_{j}\right)$ denotes a matrix of structural parameters of a pairwisemixed economy and is composed by mixing columns of a pair of matrices $\rho_{l} A_{i}, \rho_{l} A_{j}$, for any $i, j=\overline{1, S}$. 
It is also possible to derive some necessary conditions and sufficient conditions of $\delta$-stability in the structurally homogeneous case in terms of the values of eigenvalues of the matrix of structural parameters of the reduced form, $A$. It is possible by the direct application of the characteristic equation approach, when one requires that all the roots of the polynomial (that are eigenvalues of the Jacobian matrix) be less than zero for stability, the latter being equivalent to the well-known Routh-Hurwitz conditions.

Proposition 5 If all eigenvalues of $A$ are real and less than one, then the structurally homogeneous system (4) and (3) with two agents is $\delta$-stable, that is, stable under the three types of heterogeneous learning: agents with different initial perceptions with RLS or SG learning, agents with possibly different degrees of inertia with $R L S$ or $S G$ learning, and agents with different learning algorithms, RLS and $S G$. For the structurally homogeneous system (4) and (3) with any number of agents to be $\delta$-stable, it is necessary that all real roots of $A$ be less than one. This gives a test for non- $\delta$-stability.

Proof. See Appendix A.

In the proof of the proposition above, using the structure of the Jacobian matrices in our setup, we have derived a sufficient condition for stability under all three types of heterogeneous learning with two agent types. We did this using the criterion for stability of Honkapohja and Mitra (2006). For the case of real roots of $A$, we have shown that in this setup, the analysis of stability of a particular Jacobian turns into the analysis of stability of $A$, which gives us very simple eigenvalues conditions. Also, using the general criterion of Honkapohja and Mitra (2006), we have proved here the necessary conditions for $\delta$-stability (the failure of which is sufficient for non- $\delta$-stability) for the case of an arbitrary number of agent types.

\section{Optimal Policy Rules and the Structure of the Reduced Forms}

After deriving and stating the conditions for stability under the three types of heterogeneous learning discussed in the previous section, we are ready to study the general 
New Keynesian model (1), (2) and (3) for stability under heterogenous learning when optimal monetary policy rules are applied. Here we describe the types of optimal policy rules that are analyzed in this study.

The policy maker is assumed to use the loss function minimization problem, which comes from the flexible inflation targeting approach (a policy regime adopted in several countries in the 1990s), described and defended by Svensson (1999). The central bank here has two options: adopt a discretionary policy, by solving the problem every period, or commit to a rule which is once and for all derived from the minimization of the infinite horizon loss function. Svensson (1999) and Cecchetti (2001) advocate the first option, which is essentially commitment to a certain behavior (minimizing the loss function) with reconsidering the optimal rule every period, so that to take into account new information. They provide various arguments, like inefficiency (in general) of instrument rules designed to respond only to target variables or the way monetary policy decisions are made in practice.

The infinite horizon loss function of the policy maker for the flexible inflation targeting approach looks as follows.

$$
\frac{1}{2} E_{t} \sum_{i=0}^{\infty} \beta^{i}\left[\alpha\left(x_{t+i}-\bar{x}\right)^{2}+\left(\pi_{t+i}-\bar{\pi}\right)^{2}\right]
$$

According to the discussion above, we assume the discretionary policy of the policy maker and the problem of minimizing the loss function simplifies to solving each period

$$
\begin{aligned}
& \quad \min \frac{1}{2}\left[\alpha\left(x_{t}-\bar{x}\right)^{2}+\left(\pi_{t}-\bar{\pi}\right)^{2}\right]+R_{t} \\
& \text { subject to } \\
& \pi_{t}=c_{2}+\lambda x_{t}+F_{t}
\end{aligned}
$$

(the central bank takes the remainder terms of the loss function $R_{t}$, and the constraint $F_{t}=\beta \widehat{E}_{t} \pi_{t+1}+\chi_{2} w_{t}$ as given).

The classification below of the loss-function-optimization-based rules into fundamentalsbased and expectations-based rules provided below is due to Evans and Honkapohja (2003b). The derivation of these rules and the corresponding reduced forms is done by Evans and Honkapohja (2003b) for a slightly more narrow setup than is assumed 
here (we assume general structure of autoregressive shocks), therefore in the derivations that follow below we basically repeat their steps extending them for our setup.

\subsection{Expectations-based Optimal Policy Rules}

The expectations-based policy rule implies the central bank's reaction to (possibly non-rational) expectations of private agents, assuming that these expectations are observable (or can be estimated). Its general form is $i_{t}=\delta_{0}+\delta_{\pi} \hat{E}_{t} \pi_{t+1}+\delta_{x} \hat{E}_{t} x_{t+1}+$ $\delta_{w}^{\prime} w_{t}$. The coefficients of this rule are obtained by solving the equilibrium conditions: structural equations with non-rational expectations of private agents (1) and (2) and the first order conditions (FOC) of the optimization problem of the central bank (17), $\lambda\left(\pi_{t}-\bar{\pi}\right)+\alpha\left(x_{t}-\bar{x}\right)=0$. Thus, the expectations-based policy rule looks as follows:

$$
\begin{aligned}
i_{t} & =\delta_{0}+\delta_{\pi} \hat{E}_{t} \pi_{t+1}+\delta_{x} \hat{E}_{t} x_{t+1}+\delta_{w}^{\prime} w_{t}, \text { where } \\
\delta_{0} & =-\left(\lambda^{2}+\alpha\right)^{-1} \phi^{-1}\left(\lambda \bar{\pi}+\alpha \bar{x}-\lambda c_{2}-\left(\alpha+\lambda^{2}\right) c_{1}\right), \\
\delta_{\pi} & =1+\left(\lambda^{2}+\alpha\right)^{-1} \phi^{-1} \lambda \beta, \delta_{x}=\phi^{-1}, \delta_{w}=\phi^{-1} \chi_{1}+\left(\lambda^{2}+\alpha\right)^{-1} \phi^{-1} \lambda \chi_{2}
\end{aligned}
$$

After plugging this policy rule into the IS curve equation, we get the following reduced form.

$$
\begin{aligned}
& y_{t}=c^{E}+A^{E} \hat{E}_{t} y_{t+1}+\chi^{E} w_{t} \\
& w_{t}=F w_{t-1}+\nu_{t}, \\
& y_{t}=\left[\begin{array}{ll}
\pi_{t} & x_{t}
\end{array}\right]^{\prime} \text {, where } F=\operatorname{diag}\left(\rho_{i}\right),\left|\rho_{i}\right|<1, \nu_{i_{t}} \sim \operatorname{iid}\left(0, \sigma_{i}^{2}\right), i=\overline{1, n} \text {, } \\
& A^{E}=\left(\begin{array}{cc}
\beta \alpha\left(\lambda^{2}+\alpha\right)^{-1} & 0 \\
-\beta \lambda\left(\lambda^{2}+\alpha\right)^{-1} & 0
\end{array}\right) \text {, } \\
& c^{E}=\left(\begin{array}{c}
c_{2}+\lambda\left(c_{1}-\phi \delta_{0}\right) \\
c_{1}-\phi \delta_{0}
\end{array}\right), \chi^{E}=\left(\begin{array}{c}
\chi_{2}^{\prime}\left[1-\frac{\lambda^{2}}{\lambda^{2}+\alpha}\right] \\
-\frac{\lambda^{2}}{\lambda^{2}+\alpha} \chi_{2}^{\prime}
\end{array}\right)
\end{aligned}
$$

Note that the REE solution is not needed either for deriving matrix $A^{E}$, or for deriving the coefficients of the optimal expectations-based policy rule. The REE solution will be needed for deriving the optimal fundamentals-based policy rule, and therefore will be derived in the corresponding part of the text. 


\subsection{Fundamentals-based Optimal Policy Rules}

In general, the fundamentals-based policy rule (not necessarily optimal) has the form

$$
i_{t}=\psi_{0}+\sum_{i=1}^{n} \psi_{w_{i}} w_{i_{t}}=\psi_{0}+\psi_{w}^{\prime} w_{t}
$$

Later we show that there exists a unique fundamentals-based optimal policy rule in this setup and derive this rule.

Plugging this policy rule into the structural form (1) and (2), we get the following reduced form:

$$
\begin{aligned}
y_{t} & =c^{F}+A^{F} \widehat{E}_{t} y_{t+1}+\chi^{F} w_{t}, \\
w_{t} & =F w_{t-1}+\nu_{t}, \\
y_{t} & =\left[\begin{array}{cc}
\pi_{t} & x_{t}
\end{array}\right]^{\prime}, \text { where } F=\operatorname{diag}\left(\rho_{i}\right),\left|\rho_{i}\right|<1, \nu_{i_{t}} \sim i i d\left(0, \sigma_{i}^{2}\right), i=\overline{1, n}, \\
A^{F} & =\left(\begin{array}{cc}
\beta+\lambda \phi & \lambda \\
\phi & 1
\end{array}\right), \\
c^{F} & =\left(\begin{array}{c}
c_{1}-\phi \psi_{0} \\
c_{2}+\lambda\left(c_{1}-\phi \psi_{0}\right)
\end{array}\right), \chi_{F}=\left(\begin{array}{c}
\lambda\left(-\phi \psi_{w}^{\prime}+\chi_{1}^{\prime}\right)+\chi_{2}^{\prime} \\
-\phi \psi_{w}^{\prime}+\chi_{1}^{\prime}
\end{array}\right) .
\end{aligned}
$$

The optimal fundamentals-based rule, under the central banks' discretionary policy, is obtained from the loss function minimization, with the central bank assuming that private agents have RE. With the REE structure being $y_{t}=a+\Gamma w_{t}$, its general form is $i_{t}=\psi_{0}+\psi_{w}^{\prime} w_{t}$, where $w_{t}$ is a vector of exogenous variables. Using the equilibrium conditions (economy's structural equations (1) and (2), with the REE structure entering them and the FOC of the central bank's optimization problem), we obtain the coefficients of the REE and of the optimal fundamentals-based policy rule.

To get the REE, one has to write the ALM using the Phillips curve (2), the FOC of the central bank's optimization problem and the PLM in the general form, $y_{t}=a+\Gamma w_{t}$, and then according to the RE principle, equate coefficients of the resulting ALM ( $T$-mapping) with the corresponding coefficients of the PLM. The resulting ALM looks like

$$
\begin{aligned}
\pi_{t} & =\frac{c_{2}+\lambda[\lambda \bar{\pi}+\alpha \bar{x}]}{\lambda^{2}+\alpha}+\frac{\alpha \beta}{\lambda^{2}+\alpha}\left[a_{1}+\gamma_{11} \rho_{1} w_{1 t}+\ldots+\gamma_{1 n} \rho_{n} w_{n t}\right]+\frac{\alpha}{\lambda^{2}+\alpha} \chi_{2}^{\prime} w_{t} \\
x_{t} & =\frac{\lambda \bar{\pi}+\alpha \bar{x}}{\alpha}-\frac{\lambda}{\alpha} \pi_{t}
\end{aligned}
$$


and the REE looks like

$$
\begin{aligned}
\pi_{t} & =a_{1}^{*}+\sum_{i=1}^{n} \gamma_{1 i}^{*} w_{i t} \\
x_{t} & =a_{2}^{*}+\sum_{i=1}^{n} \gamma_{2 i}^{*} w_{i t}, \text { where } \\
a_{1}^{*} & =\frac{c_{2}+\lambda[\lambda \bar{\pi}+\alpha \bar{x}]}{\lambda^{2}+\alpha(1-\beta)}, a_{2}^{*}=\frac{\lambda \bar{\pi}+\alpha \bar{x}}{\alpha}-\frac{\lambda}{\alpha} a_{1}^{*}=\frac{-\frac{\lambda}{\alpha} c_{2}+(1-\beta)[\lambda \bar{\pi}+\alpha \bar{x}]}{\lambda^{2}+\alpha(1-\beta)} \\
\gamma_{1 i}^{*} & =\frac{\alpha \chi_{2 i} \rho_{i}}{\alpha\left(1-\beta \rho_{i}\right)+\lambda^{2}}, \gamma_{2 i}^{*}=-\frac{\lambda}{\alpha} \gamma_{1 i}^{*}=-\frac{\lambda \chi_{2 i} \rho_{i}}{\alpha\left(1-\beta \rho_{i}\right)+\lambda^{2}}, i=\overline{1, n}
\end{aligned}
$$

To get the optimal fundamentals-based policy rule, one has to express $i_{t}$ using the IS curve (1), plugging in it the REE solution (22) derived above.

$i_{t}=-\frac{1}{\phi}\left(a_{2}^{*}+\sum_{i=1}^{n} \gamma_{2 i}^{*} w_{i t}\right)+\left(a_{1}^{*}+\sum_{i=1}^{n} \gamma_{1 i}^{*} \rho_{i} w_{i t}\right)+\frac{1}{\phi}\left(a_{2}^{*}+\sum_{i=1}^{n} \gamma_{2 i}^{*} \rho_{i} w_{i t}\right)+\frac{1}{\phi} \chi_{1}^{\prime} w_{t}$

As a result, the optimal fundamentals-based policy rule looks like

$$
\begin{aligned}
i_{t} & =\psi_{0}^{*}+\psi_{w}^{* \prime} w_{t}, \text { where } \\
\psi_{0}^{*} & \left.=a_{1}^{*}, \psi_{w}^{*}=\frac{1}{\phi}\left[\begin{array}{lll}
\gamma_{21}\left(\rho_{1}-1\right) & \ldots & \gamma_{2 n}\left(\rho_{n}-1\right)
\end{array}\right)+\chi_{1}\right]+\left(\begin{array}{lll}
\gamma_{11} \rho_{1} & \ldots & \gamma_{1 n} \rho_{n}
\end{array}\right) .
\end{aligned}
$$

In both cases of optimal monetary policy rules, we plug the corresponding policy rule into the structural equations and obtain the corresponding reduced form of the model. These reduced forms were studied for stability under homogeneous RLS learning in the Clarida, Gali, and Gertler $(1999,2002)$ formulation of the New Keynesian model by Evans and Honkapohja (2003b), who derived the stability results for the expectations-based rule and the instability results for the fundamentals-based rule. We study stability and instability for the two categories of rules under the heterogeneous learning of private agents in the general setup of the New Keynesian model (1), (2) and (3).

\section{Stability Problem in the New Keynesian Model}

After deriving the reduced forms corresponding to the optimal monetary policy rules, we are ready to check them for $\delta$-stability. To do this we have to test the resulting matrix $A$ of the reduced form (19) or (21) for the applicability of the 
sufficient and necessary conditions for $\delta$-stability. For the situation of the optimal expectations-based policy rule we have the following result.

Proposition 6 The general New Keynesian model with a stationary AR(1) observable shocks process (1), (2) and (3) is $\delta$-stable when the optimal expectations-based policy rule (18) is applied..$^{16}$

Proof. We know that the corresponding $A$ matrix in the optimal expectationsbased policy rule case is $A^{E}=\left(\begin{array}{cc}\beta \alpha\left(\lambda^{2}+\alpha\right)^{-1} & 0 \\ -\beta \lambda\left(\lambda^{2}+\alpha\right)^{-1} & 0\end{array}\right)$. Using the sufficient condition in Proposition 4, we have that $\Omega$ is stable, since its eigenvalues are determined from the following characteristic equation $\operatorname{det}\left(A^{E}-I_{2}(1+\mu)\right)(1+\mu)^{2(S-1)}=0$ and therefore, are equal to -1 and $\beta \alpha\left(\lambda^{2}+\alpha\right)^{-1}-1$, i. e., are negative, and we have that $\operatorname{det}\left(-\rho_{l} A_{i}\right)=0,\left[\operatorname{det} \operatorname{mix}\left(-\rho_{l} A_{i},-\rho_{l} A_{j}\right)+\operatorname{det} \operatorname{mix}\left(-\rho_{l} A_{j},-\rho_{l} A_{i}\right)\right]=0$, $i \neq j, M_{1}\left(-\rho_{l} A_{i}\right)=-\rho_{l} \zeta_{h} \beta \alpha\left(\lambda^{2}+\alpha\right)^{-1} \geq(\leq) 0$, for all $l=0,1, \ldots, k\left(\rho_{0}=1\right)$, so the "same sign" condition holds true. Notice that using the "aggregate economy" sufficient condition from Proposition 3 , we can write two aggregate $\beta$-coefficients in the expectations-based policy rule case. These are $\beta_{1}^{\max }=\max _{i} \sum_{j}\left|a_{i j}\right|=$ $\max \left\{\beta \alpha\left(\lambda^{2}+\alpha\right)^{-1}, \beta \lambda\left(\lambda^{2}+\alpha\right)^{-1}\right\}$ and $\beta_{2}^{\max }=\max _{j} \sum_{i}\left|a_{i j}\right|=\beta(\alpha+\lambda)\left(\lambda^{2}+\alpha\right)^{-1}$. It is clear that both coefficients are less than one if $\lambda \geq 1$. So, the "aggregate economy" sufficient condition for $\delta$-stability is a more restrictive condition compared to the "same sign" condition since it requires additional assumptions on the structure of the economy. However, it can be with success applied in more than two dimensional economies where similar "same sign" conditions are not sufficient for $\delta$-stability (see Kolyuzhnov (2006)).

Note that Evans and Honkapohja (2003b) have a similar result for homogeneous learning. The proposition below presents the instability result for the situation of the fundamentals-based monetary policy rule.

Proposition 7 The general New Keynesian model with a stationary AR(1) observable shocks process (1), (2) and (3) is non- $\delta$-stable when the fundamentals-based

\footnotetext{
${ }^{16}$ This result is not very surprising as Evans et al. (2005) have a convergence result under the optimal expectations-based policy rule when all agents use SG learning.
} 
policy rule (20) (as well as the optimal fundamentals-based policy rule (23)) is applied.

Proof. We know that the corresponding matrix $A$ in the fundamentals-based policy rule case is $A^{F}=\left(\begin{array}{cc}\beta+\lambda \phi & \lambda \\ \phi & 1\end{array}\right)$. Using the "eigenvalues" necessary condition from Proposition 5, ${ }^{17}$ we get the eigenvalues of this matrix:. $\mu_{1,2}=1+\frac{\beta+\lambda \phi-1}{2} \pm$ $\sqrt{\left(\frac{\beta+\lambda \phi-1}{2}\right)^{2}+\lambda \phi}$. Both of these eigenvalues are real and eigenvalue $\mu_{1}=1+$ $\frac{\beta+\lambda \phi-1}{2}+\sqrt{\left(\frac{\beta+\lambda \phi-1}{2}\right)^{2}+\lambda \phi}$ is greater than one. So, the sufficient condition for non- $\delta$-stability is satisfied.

Again, Evans and Honkapohja (2003b) have a similar result for homogeneous learning.

Proposition 6 means that the REE in this model, resulting after implementing the optimal expectations-based policy rule, is stable under the recursive least squares and the stochastic gradient homogeneous learning and the three types of heterogeneous learning: agents with different initial perceptions with the RLS or SG learning, agents with different degrees of inertia with RLS or SG learning, and agents with different learning algorithms, RLS and SG. Proposition 7 claims that the REE of this model with the fundamentals-based policy rule is always unstable under any type of heterogeneous and homogeneous learning of agents.

\section{Conclusion}

We have used the environment of the New Keynesian model to explore the question of stability of two categories of optimal monetary policy rules under the assumption of heterogeneous learning of private agents.

These two categories were introduced by Evans and Honkapohja (2003b), and this division is based on the assumption about the central bank's perception of private agents' expectations: RE or possibly non-rational. Under the central bank

\footnotetext{
${ }^{17}$ In principle, we could also use our necessary conditions for $\delta$-stability (derived in Kolyuzhnov (2006)) to show the instability of the fundamentals-based rule. However, these may be more difficult to check than the necessary conditions on eigenvalues that we derived in this paper. Besides, our eigenvalues necessary conditions work for the case of an arbitrary number of agent types.
} 
assuming private agents to have RE, the fundamentals-based rule is obtained, while the case of the central bank assuming possibly non-rational expectations of private agents results in the expectations-based rule.

The purpose of this research was, on the one hand, to explore whether, given structural homogeneity of the model, heterogeneity in learning of agents influences the stability results implied by the application of either of the two categories of policy rules.

Using the general criterion for stability of Honkapohja and Mitra (2006) and the sufficient $\delta$-stability conditions derived in Kolyuzhnov (2006) for the case of heterogeneous learning, we obtain results similar to those obtained by Evans and Honkapohja (2003b) for the case of homogeneous learning. In particular, under the fundamentals-based policy rule, the model economy is always unstable, so there is no convergence to the associated REE of the model, while there is stability under the optimal expectations-based rule and the economy converges to the REE corresponding to the optimal monetary policy without commitment.

The above-described results have been obtained using only the structure of the model, so there is no dependence on heterogeneity of any type considered. This implies that in the New Keynesian model, the stability results are independent of heterogeneity in learning, so the representative agent hypothesis is applicable in this setup.

The method of analysis presented in this paper allows us to check the applicability of this hypothesis in the case of heterogeneous leaning of private agents in the New Keynesian economy under Taylor-type rules (the case of internal central bank forecasting), which do not fall under the classification of Evans and Honkapohja (2003b). This issue will be considered in a separate study.

\section{References}

Bullard, J. and Mitra, K.: 2002, Learning about monetary policy rules, Journal of Monetary Economics 49(6), 1105-29.

Calvo, G. A.: 1983, Staggered prices in a utility-maximizing framework, Journal of Monetary Economics 12, 383-398. 
Cecchetti, S. G.: 2001, Making monetary policy: Objectives and rules, Oxford Review of Economic Policy 16(4), 43-59.

Christiano, L. J., Eichenbaum, M. and Evans, C.: 2001, Nominal rigidities and the dynamic effects of a shock to monetary policy, NBER Working Paper Series w. p. 8403 .

Clarida, R., Gali, J. and Gertler, M.: 1999, The science of monetary policy: A new keynesian perspective, Journal of Economic Literature 37, 1661-1707.

Clarida, R., Gali, J. and Gertler, M.: 2002, A simple framework for international monetary policy analysis, Journal of Monetary Economics 49, 879-904.

Evans, G. W. and Honkapohja, S.: 2001, Learning and Expectations in Macroeconomics, Princeton University Press, Princeton, NJ.

Evans, G. W. and Honkapohja, S.: 2003a, Adaptive learning and monetary policy design, Journal of Money, Credit, and Banking 35(6), 1045-72.

Evans, G. W. and Honkapohja, S.: 2003b, Expectations and the stability problem for optimal monetary policy design, Review of Economic Studies 70, 807-824.

Evans, G. W., Honkapohja, S. and Williams, N.: 2005, Generalized stochastic gradient learning, CESifo Working Papers No. 1576.

Giannitsarou, C.: 2003, Heterogeneous learning, Review of Economic Dynamics 6, 885-906.

Honkapohja, S. and Mitra, K.: 2005, Performance of monetary policy rules with internal central bank forecasting, Journal of Economic Dynamics and Control 29, 627-658.

Honkapohja, S. and Mitra, K.: 2006, Learning stability in economies with heterogeneous agents, Review of Economic Dynamics 9(2), 284-309.

Johnson, C. R.: 1974, Sufficient conditions for d-stability, Journal of Economic Theory $\mathbf{9}, 53-62$. 
Kolyuzhnov, D.: 2006, Economic dynamics under heterogeneous learning: Necessary and sufficient conditions for stability. Manuscript, CERGE-EI.

Sargent, T. J.: 1993, Bounded Rationality in Macroeconomics, Oxford University Press, Clarendon Press, Oxford and New York.

Svensson, L. E. O.: 1999, Inflation targeting as a monetary policy rule, Journal of Monetary Policy 43, 607-654.

Walsh, C. E.: 2003, Monetary Theory and Policy, 2 edn, MIT Press.

Woodford, M.: 1996, Control of the public debt: A requirement for price stability, NBER Working Paper Series w.p. 5684.

Woodford, M.: 2003, Interest and Prices: Foundations of a Theory of Monetary Policy, Princeton University Press. 


\section{A Appendix}

\section{A.1 Proof of Propositions 1 and 2}

The PLM in general form is $y_{t}=a+\Gamma w_{t}$. If $w_{i}$ is not included in the PLM, it is reflected in the corresponding zero column of $\Gamma$. The REE conditions can be written as $\left(\rho_{i} A-I_{n}\right)\left[\begin{array}{lll}\gamma_{1 i} & \cdots & \gamma_{n i}\end{array}\right]^{\prime}+B^{i}=0, i \in I_{0}$.

It is clear that in case $i$ is not included into the active factors set, that is $\left[\begin{array}{lll}\gamma_{1 i} & \cdots & \gamma_{n i}\end{array}\right]^{\prime}=0$, then in order to have a REE solution, $B^{i}$ has to be equal to 0 , so that one can omit only those factors in the PLM, that have a zero column in $B$ in the reduced form. Equivalently, it is clear that if $B_{i} \neq 0$, then, in order to have a REE solution, one should not have $\left[\begin{array}{lll}\gamma_{1 i} & \ldots & \gamma_{n i}\end{array}\right]^{\prime}=0$, that is, one has to include $w_{i}$ into the active factors set.

In case $i$ is included in the active factors set, that is $\left[\begin{array}{lll}\gamma_{1 i} & \ldots & \gamma_{n i}\end{array}\right]^{\prime} \neq 0$, the REE solution exists if and only if the following conditions holds true.

$B^{i}=0$, or $\left(B^{i} \neq 0\right.$ and $\left.\operatorname{det}\left(\rho_{i} A-I\right) \neq 0\right)$, or $\left(B^{i} \neq 0\right.$ and $\operatorname{det}\left(\rho_{i} A-I\right)=0$ and $\left.\operatorname{rank}\left(\rho_{i} A-I\right)=\operatorname{rank}\left(\rho_{i} A-I, B^{i}\right)\right)$.

Combining the two cases we get the statement in Proposition 1.

For Proposition 2, one has only to transform the last conditions to guarantee the uniqueness of the solution.

In case $i$ is included in the active factors set, that is $\left[\begin{array}{lll}\gamma_{1 i} & \ldots & \gamma_{n i}\end{array}\right]^{\prime} \neq 0$, the REE solution exists and is unique if and only if the following condition holds true. $\operatorname{det}\left(\rho_{i} A-I\right) \neq 0$.

\section{A.2 Proof of Proposition 5 (Necessary conditions and suf- ficient conditions in terms of eigenvalues for the struc- turally homogeneous case)}

We have to study matrix $D_{1} \Omega_{\rho_{l}}$ for stability under any $\delta_{h}>0$, where $D_{1}$ and $\Omega_{\rho_{l}}$ are defined in (14) and (16), respectively. Thus we consider

$$
\begin{aligned}
\operatorname{det}\left(\Omega_{\rho_{l}}-D_{1}^{-1} \mu I\right) & =\operatorname{det}\left[\begin{array}{ccc}
\rho_{l} A_{1}-\left(1+\frac{\mu}{\delta_{1}}\right) I & \cdots & \rho_{l} A_{S} \\
\vdots & \ddots & \vdots \\
\rho_{l} A_{1} & \cdots & \rho_{l} A_{S}-\left(1+\frac{\mu}{\delta_{S}}\right) I
\end{array}\right]=0, \\
\forall l & =0, \ldots, k,\left(\rho_{0}=1\right),
\end{aligned}
$$


where $A_{h}=\zeta_{h} A, \sum \zeta_{h}=1$.

It is clear from the structure of the matrix above that $\mu=-\delta_{i_{0}}$ is a root if and only if at least one of the following holds true: $\bar{A}$ is singular or there exists at least one other $\delta_{j}$ that equals $\delta_{i_{0}}$. (If $A$ is singular, then $\mu_{h}=-\delta_{h}, h=\overline{1, S}$ are the roots. That is, if none of $-\delta^{\prime}$ s is the root, then $A$ is non-singular.)

Assume that $A$ is non-singular and all $\delta_{h}$ 's are different, that is assume that none of $-\delta^{\prime}$ s is the root. If there are roots other than $-\delta_{h}^{\prime} \mathrm{s}$ (the case of eigenvalues $\mu_{h}=-\delta_{h}<0$ is obvious), then they satisfy the characteristic equation for obtaining the eigenvalues of $D_{1} \Omega_{\rho_{l}}$ that are not equal to $-\delta_{h}$ :

$$
\operatorname{det}\left(\Omega_{\rho_{l}}-D_{1}^{-1} \mu I\right)=\operatorname{det}\left[\begin{array}{ccc}
\rho_{l} A_{1}-\left(1+\frac{\mu}{\delta_{1}}\right) I & \cdots & \rho_{l} A_{S} \\
\vdots & \ddots & \vdots \\
\rho_{l} A_{1} & \cdots & \rho_{l} A_{S}-\left(1+\frac{\mu}{\delta_{S}}\right) I
\end{array}\right]=
$$

(subtracting the last row from other rows)

$=\operatorname{det}\left[\begin{array}{ccccc}-\left(1+\frac{\mu}{\delta_{1}}\right) I & 0 & \cdots & 0 & \left(1+\frac{\mu}{\delta_{S}}\right) I \\ 0 & -\left(1+\frac{\mu}{\delta_{2}}\right) I & \cdots & 0 & \left(1+\frac{\mu}{\delta_{S}}\right) I \\ \vdots & \vdots & \ddots & \vdots & \vdots \\ 0 & 0 & \cdots & -\left(1+\frac{\mu}{\delta_{S-1}}\right) I & \left(1+\frac{\mu}{\delta_{S}}\right) I \\ \rho_{l} A_{1} & \rho_{l} A_{2} & \cdots & \rho_{l} A_{S-1} & \rho_{l} A_{S}-\left(1+\frac{\mu}{\delta_{S}}\right) I\end{array}\right]=$

$\left(\right.$ for $\left.\mu \neq \delta_{h} \forall h\right)$

$$
=\left(1+\frac{\mu}{\delta_{1}}\right) \times \ldots \times\left(1+\frac{\mu}{\delta_{S}}\right) \operatorname{det}\left[\begin{array}{cccc}
-I & \cdots & 0 & I \\
\vdots & \ddots & \vdots & \vdots \\
0 & \cdots & -I & I \\
\frac{\rho_{l} A_{1}}{\left(1+\frac{\mu}{\delta_{1}}\right)} & \cdots & \frac{\rho_{l} A_{S-1}}{\left(1+\frac{\mu}{\delta_{S-1}}\right)} & \frac{\rho_{l} A_{S}}{\left(1+\frac{\mu}{\delta_{S}}\right)}-I
\end{array}\right]=
$$

(adding all columns to the last one)

$=\left(1+\frac{\mu}{\delta_{1}}\right) \times \ldots \times\left(1+\frac{\mu}{\delta_{S}}\right) \operatorname{det}\left[\begin{array}{cccc}-I & \cdots & 0 & 0 \\ \vdots & \ddots & \vdots & \vdots \\ 0 & \cdots & -I & 0 \\ \frac{\rho_{l} A_{1}}{\left(1+\frac{\mu}{\delta_{1}}\right)} & \cdots & \frac{\rho_{l} A_{S-1}}{\left(1+\frac{\mu}{\delta_{S-1}}\right)} & {\left[\frac{\rho_{l} A_{1}}{1+\frac{\mu}{\delta_{1}}}+\ldots+\frac{\rho_{l} A_{S}}{1+\frac{\mu}{\delta_{S}}}-I\right]}\end{array}\right]=$ 


$$
=\left(1+\frac{\mu}{\delta_{1}}\right) \times \ldots \times\left(1+\frac{\mu}{\delta_{S}}\right)(-1)^{n(S-1)} \operatorname{det}\left[\frac{\rho_{l} A_{1}}{1+\frac{\mu}{\delta_{1}}}+\ldots+\frac{\rho_{l} A_{S}}{1+\frac{\mu}{\delta_{S}}}-I\right]=0 .
$$

As we consider $\mu \neq-\delta_{h}$, the last equation is equivalent to

$$
\operatorname{det}\left[\frac{-\rho_{l} A_{1}}{1+\frac{\mu}{\delta_{1}}}+\ldots+\frac{-\rho_{l} A_{S}}{1+\frac{\mu}{\delta_{S}}}+I\right]=0 \text {, where } A_{h}=\zeta_{h} A, \sum \zeta_{h}=1 \text {. }
$$

After some calculations, we obtain

$$
\operatorname{det}\left[\rho_{l} A\left(\frac{-\zeta_{1}}{1+\frac{\mu}{\delta_{1}}}+\ldots+\frac{-\zeta_{S}}{1+\frac{\mu}{\delta_{S}}}\right)+I\right]=0
$$

and finally

$$
\rho_{l} \lambda_{k}\left(\frac{\zeta_{1}}{1+\frac{\mu}{\delta_{1}}}+\ldots+\frac{\zeta_{S}}{1+\frac{\mu}{\delta_{S}}}\right)=1
$$

for those $\lambda_{k}$, eigenvalues of $A$, that are not equal to zero. If all $\lambda_{k}=0$, then $A$ is a zero matrix and the only eigenvalues of $D \Omega$ are $-\delta_{h}$ 's.

As complex eigenvalues of a real matrix $A$ come in conjugate pairs, the system above is equivalent to

$$
\left\{\begin{array}{c}
\rho_{l} \operatorname{Re}\left(\lambda_{k}\right) \operatorname{Re}\left(\frac{\zeta_{1}}{1+\frac{\mu}{\delta_{1}}}+\ldots+\frac{\zeta_{S}}{1+\frac{\mu}{\delta_{S}}}\right)-\rho_{l} \operatorname{Im}\left(\lambda_{k}\right) \operatorname{Im}\left(\frac{\zeta_{1}}{1+\frac{\mu}{\delta_{1}}}+\ldots+\frac{\zeta_{S}}{1+\frac{\mu}{\delta_{S}}}\right)=1 \\
\rho_{l} \operatorname{Im}\left(\lambda_{k}\right) \operatorname{Re}\left(\frac{\zeta_{1}}{1+\frac{\mu}{\delta_{1}}}+\ldots+\frac{\zeta_{S}}{1+\frac{\mu}{\delta_{S}}}\right)+\rho_{l} \operatorname{Re}\left(\lambda_{k}\right) \operatorname{Im}\left(\frac{\zeta_{1}}{1+\frac{\mu}{\delta_{1}}}+\ldots+\frac{\zeta_{S}}{1+\frac{\mu}{\delta_{S}}}\right)=0
\end{array}\right.
$$

for each pair of conjugate eigenvalues. In case of a real eigenvalue, $\operatorname{Im}\left(\lambda_{k}\right)=0$, the corresponding system simplifies to

$$
\rho_{l} \operatorname{Re}\left(\lambda_{k}\right)\left(\frac{\zeta_{1}}{1+\frac{\mu}{\delta_{1}}}+\ldots+\frac{\zeta_{S}}{1+\frac{\mu}{\delta_{S}}}\right)=\rho_{l} \lambda_{k}\left(\frac{\zeta_{1}}{1+\frac{\mu}{\delta_{1}}}+\ldots+\frac{\zeta_{S}}{1+\frac{\mu}{\delta_{S}}}\right)=1
$$

For any $S$ we have that for eigenvalues $\mu$ to be negative, it is necessary that

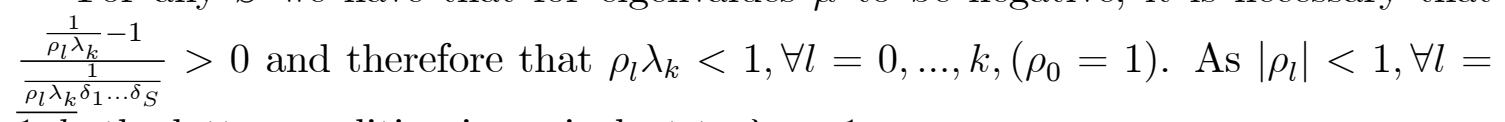
$\overline{1, k}$, the latter condition is equivalent to $\lambda_{k}<1$.

For $S=2$, the system corresponding to a real eigenvalue looks as follows:

$$
\left\{\begin{array}{l}
\rho_{l} \lambda_{k}\left(\frac{\zeta_{1}}{1+\frac{\mu}{\delta_{1}}}+\frac{\zeta_{2}}{1+\frac{\mu}{\delta_{2}}}\right)=1 \\
\mu^{2}+\mu \frac{\frac{1}{\rho_{l} \lambda_{k}}\left(\frac{1}{\delta_{1}}+\frac{1}{\delta_{2}}\right)-\left(\frac{\zeta_{1}}{\delta_{2}}+\frac{\zeta_{2}}{\delta_{1}}\right)}{\frac{1}{\rho_{l} \lambda_{k} \delta_{1} \delta_{2}}}+\frac{\frac{1}{\rho_{l} \lambda_{k}}-1}{\frac{1}{\rho_{l} \lambda_{k} \delta_{1} \delta_{2}}}=0
\end{array}\right.
$$


The Routh-Hurwitz conditions for negativity of real parts of $\mu$ are necessary and sufficient and look as follows:

$$
\left\{\begin{array}{l}
\frac{\frac{1}{\rho_{l} \lambda_{k}}-1}{\frac{1}{\rho_{l} \lambda_{k} \delta_{1} \delta_{2}}}>0 \\
\frac{\frac{1}{\rho_{l} \lambda_{k}}\left(\frac{1}{\delta_{1}}+\frac{1}{\delta_{2}}\right)-\left(\frac{\zeta_{1}}{\delta_{2}}+\frac{\zeta_{2}}{\delta_{1}}\right)}{\frac{1}{\rho_{l} \lambda_{k} \delta_{1} \delta_{2}}}>0
\end{array} .\right.
$$

The system of inequalities above is equivalent to

$$
\left\{\begin{array}{c}
\rho_{l} \lambda_{k}<1 \\
\rho_{l} \lambda_{k}<\frac{\frac{1}{\delta_{1}}+\frac{1}{\delta_{2}}}{\frac{\zeta_{1}}{\delta_{2}}+\frac{\zeta_{2}}{\delta_{1}}} .
\end{array} .\right.
$$

Since $\frac{\frac{1}{\delta_{1}}+\frac{1}{\delta_{2}}}{\frac{\zeta_{1}}{\delta_{2}}+\frac{\zeta_{2}}{\delta_{1}}}>1$, as $\frac{1-\zeta_{1}}{\delta_{1}}+\frac{1-\zeta_{2}}{\delta_{2}}>0$, the last system of inequalities is equivalent to $\rho_{l} \lambda_{k}<1, \forall l=0, \ldots, k,\left(\rho_{0}=1\right)$. As $\left|\rho_{l}\right|<1, \forall l=\overline{1, k}$, the latter condition is equivalent to $\lambda_{k}<1$.

Thus, we get the sufficient condition for stability for the case of $S=2$, that all eigenvalues of $A$ are real and less than 1; and the necessary condition for stability for any $S$ is that all real eigenvalues of $A$ have to be less than 1. Q.E.D. 
Individual researchers, as well as the on-line and printed versions of the CERGE-EI Working Papers (including their dissemination) were supported from the following institutional grants:

- Center of Advanced Political Economy Research [Centrum pro pokročilá politickoekonomická studia], No. LC542, (2005-2009),

- Economic Aspects of EU and EMU Entry [Ekonomické aspekty vstupu do Evropské unie a Evropské měnové unie], No. AVOZ70850503, (2005-2010);

- Economic Impact of European Integration on the Czech Republic [Ekonomické dopady evropské integrace na ČR], No. MSM0021620846, (2005-2011);

Specific research support and/or other grants the researchers/publications benefited from are acknowledged at the beginning of the Paper.

(c) Anna Bogomolova , Dmitri Kolyuzhnov, 2008.

All rights reserved. No part of this publication may be reproduced, stored in a retrieval system or transmitted in any form or by any means, electronic, mechanical or photocopying, recording, or otherwise without the prior permission of the publisher.

Published by

Charles University in Prague, Center for Economic Research and Graduate Education (CERGE) and

Economics Institute ASCR, v. v. i. (EI)

CERGE-El, Politických vězňů 7, 11121 Prague 1, tel.: +420 224005 153, Czech Republic.

Printed by CERGE-EI, Prague

Subscription: CERGE-EI homepage: http://www.cerge-ei.cz

Editors: Directors of CERGE and EI

Managing editors: Deputy Directors for Research of CERGE and EI

ISSN 1211-3298

ISBN 978-80-7343-180-8 (Univerzita Karlova. Centrum pro ekonomický výzkum

a doktorské studium)

ISBN 978-80-7344-169-2 (Národohospodářský ústav AV ČR, v. v. i.) 
CERGE-EI

P.O.BOX 882

Politických vězňů 7

11121 Praha 1

Czech Republic http://www.cerge-ei.cz 